\title{
ROBÓTICA EDUCACIONAL E A MATEMÁTICA: UM PROJETO DE EXTENSÃO NO INTERIOR DO CERRADO DE GOIÁS
}

\author{
Beatriz Siqueira Ribeiro ${ }^{1}$ \\ Fernando da Costa Barbosa ${ }^{2}$
}

\begin{abstract}
Resumo: O presente artigo apresenta uma experiência vivenciada em uma das ações realizadas pelo projeto de extensão que ocorre na Universidade Federal de Goiás - Regional Catalão, intitulado "ROBOMAT: Construindo cenários de Matemática com Robótica Educacional". Este projeto tem como objetivo, promover ações que envolvem a interação entre a universidade e comunidade. Além disso despertar nos alunos a vontade e encantamentono processo de aprendizagem matemática. Nessa perspectiva viu-sena RobóticaEducacional uma forma de potencializar o ensino e aprendizagem de matemática de forma lúdica de alunos da rede pública de ensino. Para tanto, foi realizado uma atividade envolvendo robótica e conhecimento matemático para alunos dos primeiros anos do ensino fundamental II. Como resultado deste estudo, discutiu-se a importância de uso de tecnologias na educação, como forma de ferramenta didática.
\end{abstract}

Palavras-chave: Aprendizagem Matemática. Extensão e cultura. Robótica Educacional.

Abstract: This article presents an experience lived in one of the actions carried out by the extension project that takes place at the Federal University of Goiás - Regional Catalão, entitled "ROBOMAT: Building Scenarios of Mathematics with Educational Robotics". This project aims to promote actions that involve the interaction between the university and the community. Also awaken in students the will and enchantment in the process of mathematical learning. From this perspective, one can see in Educational Robotics a way of enhancing the teaching and learning of mathematics in a playful way of students of the public school system. For that, an activity involving robotics and mathematical knowledge was carried out for students from the first years of elementary school II. As a result of this study, the importance of using technologies in education as a form of didactic tool was highlighted.

Keywords: Mathematical Learning. Extension and culture. Educational Robotics.

\section{Considerações Iniciais}

A robótica tem seus vestígios desde a história antiga, "quando os mitos faziam referência a mecanismos que ganhavam vida" (MAHMUD, 2017, p. 22), no entanto, a mídia dissemina como se fosse algo mais recente, mas no período egípcio já se tinha vestígios da robótica. Segundo Silva (2009, p. 26) os povos antigos já demonstravam o desejo por protótipos que possuíam movimentos ou que pudessem até mesmo facilitar a execução de tarefas complexas, que podemos chamar de robôs.

A palavra robô resulta de combinação das palavras tchecas robota, que significa “trabalho obrigatório", e robotnik, que significa “servo”. Grande parte dos robôs atuais está de fato realizando um trabalho obrigatório, na forma de tarefas repetitivas e rígidas, tais como a montagem de automóveis (MATARIC, 2014, p. 17)

Somente no século XX, com o avanço das tecnologias desenvolvidas na Revolução Industrial, a robótica ganhou sua nomeação, e começou a se tornar parte dos meios tecnológicos que estavam em avanço, com o desejo que constituísse de uma ferramenta que trouxesse facilidade

\footnotetext{
${ }^{1}$ Graduanda em matemática licenciatura pela Universidade Federal de Goiás/Regional Catalão - UFG e Bolsista do PROBEC. E-mail: beatriz_ribeiro15@hotmail.com

${ }^{2}$ Docente na Unidade Acadêmica Especial de Matemática e Tecnologia (IMTec) da Universidade Federal de Goiás/Regional Catalão - UFG, Doutor em Educação pela Universidade Federal de Uberlândia - UFU. E-mail: 
em diversos momentos e espaço. Assim, podemos definir a robótica como sendo "a ciência ou o estudo da tecnologia associado com o projeto, fabricação, teoria e aplicação dos robôs" (SILVA, 2009, p. 27). 
Podemos observar que as tecnologias podem estar presentes para ajudar também no ensino-aprendizagem dos alunos, pois estes na maioria, já estão familiarizados com o uso dos recursos tecnológicos em seu cotidiano. Barbosa (2016, p.29) diz que "precisamos nos apropriar das tecnologias, para o desenvolvimento humano, capazes de criar, questionar, investigar, estabelecer conexões de conhecimento, produzir e ser independentes em sua vida”.

Neste viés temos a Robótica Educacional (RE), que traz uma abordagem tecnológica e didática necessária para desenvolver aulas mais interativas e lúdicas através da tecnologia, visando buscar o interesse dos alunos em aprender, além deles mesmos se tornarem autores do seu conhecimento, pois os mesmos constroem o protótipo, programam e o estudam.

A robótica educacional é uma atividade desafiadora e lúdica, que utiliza o esforço do educando na criação de soluções de hardware e software visando a resolução de uma situação-problema proposto. Alguns projetos pedagógicos de robótica em sala de aula fazem uso, por exemplo, da teoria construtivista de Jean Piaget para auxiliar o processo de ensino permitindo ao aluno, no processo de construção do conhecimento, a oportunidade de participar de uma aprendizagem mais efetiva e desenvolver uma percepção mais acurada dos fenômenos científicos. (MIRANDA, SAMPAIO, BORGES, 2010, p. 47)

Nosso trabalho com Robótica Educacional é um ambiente de aprendizagem que se divide em duas etapas principais, a Montagem e Programação. É no processo de montagem que o aluno constrói sua interação física com o robô, entendendo suas partes e seu todo, de forma a compreender suas funcionalidades práticas para a execução de uma tarefa, nesse processo desperta também no aluno o trabalho em equipe e a autonomia,

[...] na construção de um modelo robótico, o processo de colaboração acontece quando os problemas são analisados e resolvidos em grupo e a autonomia é exercida na medida em que cada elemento do grupo tem responsabilidade por uma parte da solução, e no respeito a outros indivíduos. (SILVA, 2009, p. 31).

No momento de programação, devido à ludicidade dos protótipos, é potencializado o raciocínio lógico e a abstração, especificidades que são desenvolvidas a partir da aplicação de conhecimentos científicos prévios, concedendo ao aluno compreender como se constitui o pensamento, o sujeito se torna um epistemólogo (PAPERT, 1985). Também, para Papert (2008), é a partir do desenvolvimento dessas habilidades que o aluno começa a entrar no mundo da robótica. 
Através da robótica temos uma oportunidade de explorar a matemática com os alunos, desenvolvendo uma pratica educativa antenada a necessidade do aluno desta sociedade da cultura digital. Papert (2008) nos ensina que as tendências por si, não vão fazer o aluno escrever e desenvolver maravilhosamente uma fórmula ou conta matemática ou utilizar habilidades superiores as que já possuem, o que os alunos irão adquirir são habilidades que já lhes pertenciam, porém, potencializadas.

Assim, pensando no desenvolvimento do pensamento matemático e científico com a Robótica Educacionalé que se constituiu uma ação de extensão para alunos do ensino fundamental e médio de uma cidade do interior de Goiás, oportunizando o estreitamento da relação comunidade e universidade.Éessa prática ex tensionista que buscaremos apresentar e compartilhar neste artigo, desde sua formação até aos resultados construídos ao longo doprojeto.

\section{Metodologia}

Este projeto de extensão permitiu aos pesquisadores um contato próximo com o objeto de estudo e seu ambiente, e orientados sobre uma perspectiva de pesquisa qualitativa de Rey (2005, p. 105) temos "um processo aberto submetido a infinitos e imprevisíveis desdobramentos, cujo centro organizador é o modelo que o pesquisador desenvolve e em relação ao quais as diferentes informações empíricas adquirem significados”.

Como recurso de coleta de dados foram aplicados questionários ao final de cada atividade, e foram colhidas folhas com anotações de cálculos realizadas pelos alunos. Durante todo o processo foi realizado pelo autor notas de campo dos acontecimentos realizados. Todos os dados coletados foram analisados sobre uma abordagem qualitativa.

A partir deste pensamento, constituímos e executamos o projeto de extensão denominado "ROBOMAT: Construindo cenários de Matemática com Robótica Educacional”, submetido e aprovado no edital Programa de Bolsas de Extensão e Cultura PROBEC 2017/2018 da Universidade Federal de Goiás - Regional Catalão, ligado a Unidade Acadêmica Especial de Matemática e Tecnologia. Este projeto também foi submetido ao Comitê de Ética e Pesquisa da universidade, com cadastro de $n^{\circ} 72045417.6 .0000 .5083$ e aprovado para execução. Além disso, o projeto foi contemplado com bolsa de extensão para um aluno (a) de licenciatura.

Os principais objetivos foram motivar e despertar o interesse dos alunos e professores da Educação Básica para o ensino e aprendizagem de Matemática, por meio da contextualização e do uso das tecnologias na sala de aula. Além disso, o projeto almejou ser uma ponte de cultura e conhecimentoentre universidade e comunidade. Paratal realização, o usoda RobóticaEducacional no projeto foi essencial para desenvolver conteúdos de matemática e física, Zilli (2004) nos ensina 
que a Robótica Educacional tem as ferramentas necessárias para potencializar o processo de ensino e aprendizagem matemática dos alunos, pois sua proximidade com o cotidiano potencializa o processo de aprendizagem, permitindo o diálogo e participação, possibilitando trabalhar de forma lúdica, conectando conceitos e assim ampliando as possibilidades de aprendizagem.

O projeto foi executado dentro da universidade, nos laboratórios da Unidade Acadêmica Especial de Matemática e Tecnologia, que possuem em sua estrutura computadores e kits proprietários de Robótica Educacional adquiridos no processo de expansão da universidade e projetos com fomento. O projeto trabalha com os kits de robótica LEGO® Mindstorms NXT 2.0, desenvolvidos segundo Barbosa (2016), pelo pesquisador e Matemático Seymour Papert do MIT (Massachusetts Institute of Technology) e a empresa de brinquedos LEGO®. Hoje já existe a divisão da empresa, tendo a LEGO® Educacional, responsável pela produção de materiais específicos para educação, como os kits de robótica.

Para execução do projeto de extensão a universidade também contribuiu com a disponibilidade de translato para que os alunos pudessem se deslocar até a universidade, conhecer e participar da iniciativa. As ações aconteceram durante dois semestres, sendo o primeiro período de agosto à dezembro de 2017, no qual recebeu o total de 92 alunos, sendo 12 alunos da cidade de Ouvidor - GO e o restante dos alunos de escolas de Catalão - GO. O segundo período em 2018 com retorno das aulas, até o mês de junho, tivemos 43 alunos que puderam fazer parte do projeto, todos da cidade de Catalão - GO. Fomos beneficiados em receber alunos em diferentes anos letivos, desde $6^{\circ}$ ano do fundamental II ao $1^{\circ}$ ano do ensinomédio.

Durante a participação das escolas parceiras que puderam se envolver com a iniciativa, compareciam aproximadamente 15 (quinze) alunos por encontro, os quais foram divididos em duplas ou trios e a cada período de encontros recebíamos alunos de uma escola distinta. Essa divisão tinha ligação a quantidade de material, a disposição dos computadores do laboratório e permitir o acesso de todos ao kit, tanto que o máximo de integrantes foi de três.

As atividades foram elaboradas e aplicadas considerando o desconhecimento do material e de qualquer linguagem de programação. A Matemática nas atividades era evidenciada gradativamente no decorrer dos encontros, desde noções básicas dos números reais, com medidas, operações básicas, situação pratica envolvendo circunferência, formas geométricas e até função. Havia um resgate de conhecimentos já estudados e alguns novos. Toda atividade era pensada na ótica do ano escolar do aluno. Cada encontro definiria as próximas ações elaboradas, ou seja, os resultados finais de cada dia determinavam se as próximas atividades, já elaboradas, estavam adequadas a aplicação com aqueles alunos. 
A Matemática foi evidenciada, exploradae trabalhada emum processo completo, que passa desde a montagem, programação e resolução de desafios propostos pelos professores. A partir destes desafios que os alunos começavam a conjecturar, testar hipóteses e principalmente recorrer a uma ação sistemática de resolução, que oportunizava a relação com conceitos Matemáticos da educação básica.

\section{Desenvolvimento}

O presente relato de experiência do projeto de extensão, será realizado a partir de uma das atividades desenvolvidas dentre os sete protótipos de robôs construídos ao longo do projeto, a ação proposta foi desenvolvida para atender alunos do $6^{\circ}$ e $7^{\circ}$ ano do Ensino Fundamental II. A atividade selecionada e seu respectivo protótipo foi aplicada a quatro turmas de $6^{\circ}$ ano e uma turma do $7^{\circ}$ ano do ensino fundamental, sendo estes alunos de quatro escolas distintas, localizadas na cidade de Catalão-Go, porém aqui será apresentado uma das turmas. O relato em questão ocorreu em uma turma de 14 alunos do $6^{\circ}$ ano do ensino fundamental, e foi realizado em dois dias distintos

Durante a atividade foram analisados nos alunos três processos: montagem, programação e resolução da proposta de atividade, os objetivos de cada etapa é:

- Na montagem foi analisado o desempenho dos alunos no processo de montagem, como eles dividiram as tarefas entre os colegas e se estão com dificuldade para compreender o passo a passo disponibilizado, esse momento algumas dificuldades sãopercebidas, comolateralidade, visualização espacial dafigurae transposiçãono objeto real.

- Durante o processo de programação foi analisado a aptidão dos alunos com a tecnologia, como eles desenvolvem a lógica de programação e o trabalho de equipe para o desenvolvimento da mesma, já que esta parte esta totalmente ligada a próximo eixo.

- Para a resolução da atividade/desafio proposto os alunos tinham que desenvolver uma divisão de tarefas entre os membros, e o fluxo de trabalho foi analisado, como também odesenvolvimento dos cálculos necessários e como foi repassado os dados obtidos para a programação do protótipo.

Considerando o conhecimento dos mesmos sobre a Robótica Educacional, foi realizado uma dinâmica educativa, que tinha uma breve introdução, onde esta abordava aspectos históricos da Robótica e uma conversa para entender o que cada aluno entendia sobre o conceito de robótica. Em seguida ocorreu um momento de familiarização com o kit, ou seja, os alunos foram levados a conhecer as peças que constituíam o kit e qual a finalidade das mesmas. Feito isso, iniciou-se a 
montagem do primeiro protótipo robótico. O protótipo escolhido para a realização da proposta de atividade foi do robô denominado Castor Bot (Imagem 1).

Imagem 1: protótipo montado.

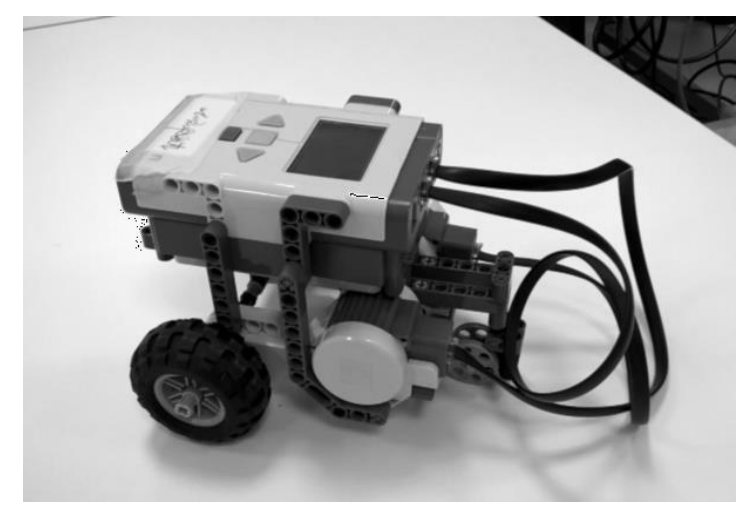

Fonte: Próprio autor

Este robô foi escolhido para ser desenvolvido na primeira aula por possuir um processo de montagem rápido e que utiliza de poucas peças, com isso os alunos conseguiriam se familiarizar com o processo de montagem de forma gradativa, partindo de uma montagem mais simples a uma mais complexa. Antecipadamente a cada encontro as peças a serem utilizadas na construção do protótipo são separadas e colocados em uma bandeja, para agilizar o processo de montagem pelos alunos.

\section{A atividade}

A montagem do Castor Bot foi realizada com auxílio do passo a passo, ou melhor, um projeto $^{1}$. Como haviam 14 alunos presentes, foram separadas sete duplas, e distribuídas sete bandejas. No geral os alunos dividiram a função com sua dupla, por exemplo, um ficava olhando no computador o projeto e já separava as peças que seriam necessárias, enquanto o colega ia montando a partir da representação do passo a passo. Visto que era o primeiro contato, foram instigados a trocarem de funções ao longo da montagem para que todos pudessem montar o protótipo.

Para a maioria das duplas a montagem foi executada rapidamente, observamos que apenas duas duplas tiveram um pouco de dificuldade, levando mais tempo para realizar o processo de montagem, a razão detectada foi dificuldade na visão espacial do robô e domínio de lateralidade dos objetos. A medida que cada dupla terminava a montagem, eram orientados a explorar seus robôs, aprendendo como era seu funcionamento.

Imagem 2: alunos realizando a montagem com auxilio do projeto.

1 O projeto da montagem do protótipo é de uso livre e disponível em: <http://www.nxtprograms.com/castor_bot/index.html> acesso em 05 de julho de 2018. 


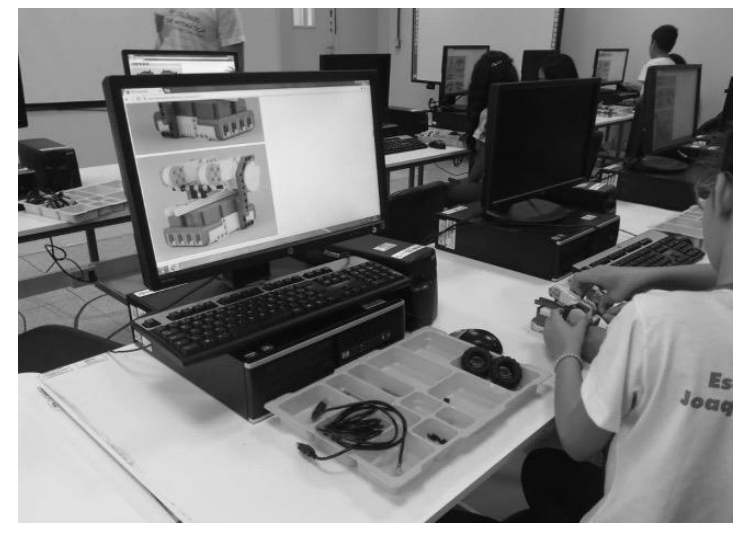

Fonte: Próprio autor

Este momento foi muito especial para os alunos, pois este era o primeiro robô construído pelas mãos deles, e ao terminar a montagem e ver o que haviam feito, externavam deslumbre e orgulho de si mesmos e de seus colegas.

Após finalização da montagem, foi elaborada uma breve explicação do software que seria utilizado para programar o protótipo, denominado Mindstorms NXT 2.0. O software utilizado permite realizar uma programação em blocos, possibilitando assim uma programação mais intuitiva e atrativa, usando de ícones para programar. Foi especialmente desenvolvido para iniciar programação com crianças. Neste software os alunos aprendem a orientar o robô em uma execução de uma ação. Quando compreendem as funcionalidades e a linha de raciocínio lógico, começavam a "ensinar" a máquina a realizar funções, as quais eles formularam.

Após este momento, foi lançado o primeiro desafio: Fazer o Castor Bot andar para frente e depois para trás. Estes primeiros desafios tinham por objetivo de leva-los a entender a lógica de programação por trás do software, a função dos ícones e do próprio software de programação. É uma oportunidade de testarem suas hipóteses, à medida que experimentavam novas ações, mais complexas se tornavam seus próprios desafios.

Eles mesmos se desafiavam a fazer mais com que aprenderam, ou seja, cientes que os motores são programáveis por dados como graus, número de rotações e quantidade de tempo, há três formas de “ensinar” o robô a se locomover. Três variáveis, três dados quantitativos que podem ser inseridos aleatoriamente ou minuciosamente calculado se pensado em uma ação com precisão. Assim, por tentativa e erro, exploraram o desconhecido e formulando respostas as suas inquietações, até onde ele vai se programado para andar 10 segundos? E quantas rotações seriam para percorrer a mesma distância?

O segundo desafio veio como pergunta: como faço para que meu robô percorra exatamente 1 metro (100 centímetros)? Percebam que há uma cobrança de precisão, exatidão que pode ser solucionada por tentativa ou por Matemática. Para isso foi disponibilizado fitas métricas, para que os alunos pudessem medir a distância a ser percorrida, hora de rever e trabalhar com leitura de 
unidades de medidas, conversão, valores decimais, números reais. Marcarummetroenvolveleitura de um instrumento de medida, conversão de unidades. Esse foi o primeiro passo, todos alunos tentaram programar seus robôs, e neste momento veio o primeiro questionamento: como programar se o programa só dá opção de medidas em graus, rotação e segundo?

O problema estava posto, mas a solução deveria ser deles inicialmente, o papel do professor nesse processo é orientar, mas inicialmente foram deixados livres para criar suas estratégias. Os alunos preferiram tentar em segundos. A solução para o problema tinha diferentes caminhos, mas todos teriam um resultado positivo. Esse desdobramento é que muitas vezes não é percebido pelo professor, temos uma solução matemática, mas não expandimos nosso olhar para as outras soluções, como foi a escolhida pelos alunos. O uso do tempo é oportunidade de trabalhar proporcionalidade, regra de três, multiplicação, divisão com números decimais e reais. Se o robô percorre supostamente em 5 segundos, 25 centímetros, calculando, pode se chegar ao tempo exato para percorrer 100 centímetros.

Nossa visão limitada da aula, é que nos permitiu aprender com ela, pois a solução dos alunos recaíram em registrar no cronômetro o tempo gasto até atingir a distância e depois fazer ajustes para mais ou para menos nos testes seguintes. Somente após aplicarmos, percebemos o leque de oportunidade educacional daquela simples aula.

Os alunos testaram várias programações, alterando tempo de rotação e força do motor. Todos conseguiram concluir o desafio, porém obtiveram resultados diferentes, pois alguns usaram menos tempo e mais força e outros, menos força e mais tempo. Em seguida, foi realizada uma explicação, sobre como eles poderiam resolver o mesmo desafio de forma mais precisa e rápida, e para isso precisariam do conhecimento matemático.

Para a resolução de tal desafio, necessitou conhecere entendero conceito de circunferência (formalização que só seria visto nos anos seguintes), de raio ( $\square)$ e a aproximação do valor de pi $(\square)$, com duas casas decimais após a vírgula, deste modo os alunos foram instigados a medir o raio dos pneus e calcular o valor da circunferência, e em seguida comparar medida a circunferência em si com afita métrica, todos chegaram a valores bem aproximados, e entraram em consenso que poderíamos utilizar da formula da circunferência: $\square=2 \cdot \square \cdot$

Em seguida compreenderam que cada rotação que o motor realizava, era equivalente a medida da circunferência da roda. Essa abordagem é uma forma prática de apresentar a formalização do cálculo de circunferência os quais são ensinados normalmente de forma mecânica e desconexos do cotidiano.

Portanto chegou-se à conclusão que para que o protótipo realize um percurso desejado com mais exatidão, poderíamos calcular quantas rotações seriam necessárias, bastava medir a 
circunferência da roda do robô e após ter esse valor, dividir a distância que almeja pelo tamanho da circunferência. Assim todos os grupos fizeram os cálculos, alguns obtiveram bastante dificuldade em realizar a divisão, conseguindo somente com ajuda de um professor. O que nos deixou restritos foi em uma única resposta certa.

Após a finalização do desafio anterior, outro foi lançado: como faço para o robô percorrer $100 \mathrm{~cm}$ e depois virar à direita? Imediatamente todos começaram a realizar testes, e um dos grupos observou que para que o robô vire é necessário que uma de suas rodas fique parada (neste caso a roda direita), e assim fez, porém, seu robô girou inúmeras vezes em torno de seu eixo, percebendo isso, diminuiu a quantidade de rotações, logo o robô realizou uma pequena curva para a direta, concluindo sua observação, mostrou seu resultado para os outros colegas, ajudando-os a concluir o desafio. Assim que todos realizaram os testes encerramos a primeira aula.

Este primeiro encontro, pôde se notar como os alunos ficaram animados em controlar e ensinar seu robô, e o mais importante, conseguiram entender que a programação acontece de forma cronológica, e que quando um comando é dado e executado, o robô só fará o próximo comando quando o anterior for executado por completo e assim sucessivamente, desde modo estavam aprendendo mais um conceito de lógica.

No encontro seguinte foi relembrado as ações e aprendizagens da aula anterior, em seguida foi realizada uma explicação, de como fazer o robô realizar o movimento de giro do seu corpo com exatidão, por exemplo $90^{\circ}$. Isso foi possível, através da matemática. Para calcular quantas rotações são necessárias para que o robô realize uma curva, é preciso calcular a circunferência (porém neste caso o raio deverá ser a distância entre as duas rodas do robô), multiplicar o resultado pelo ângulo desejado, e por fim dividir por $360^{\circ}$. Esses cálculos podem ser vistos em Barbosa (2016, p. 361). Durante o desenvolvimento da solução deste tipo de problema, termos e conceitos matemáticos são abordados, como ângulos, arco, círculo e cálculo de circunferência.

Para finalizar a atividade envolvendo Castor Bot, foi lançado o último desafio, no chão foi colado com itas adesivas coloridas, algumas linhas, onde estas, formavam um quadrado, um retângulo e um triângulo retângulo. Os alunos deveriam programar seus robôs para que percorresse o perímetro dos polígonos.

Odesafio motivou os alunos, tanto logojá foram para o chão realizar a medições necessária, alguns mediram todos os lados de todos os polígonos para depois realizar os cálculos e programações, já outros preferiram escolher um dos polígonos, realizar os cálculos deste e programar e depois repetir o processo em outro polígono. 
No geral os alunos não demonstraram dificuldade em realizar os cálculos para que o robô realizasse a curva, mas sim em identificar o valor do ângulo do triângulo. O quadrado e o retângulo eles recordaram como 90 graus, a partir de explicações dadas na aula anterior.

Imagem 3: representação do triângulo retângulo

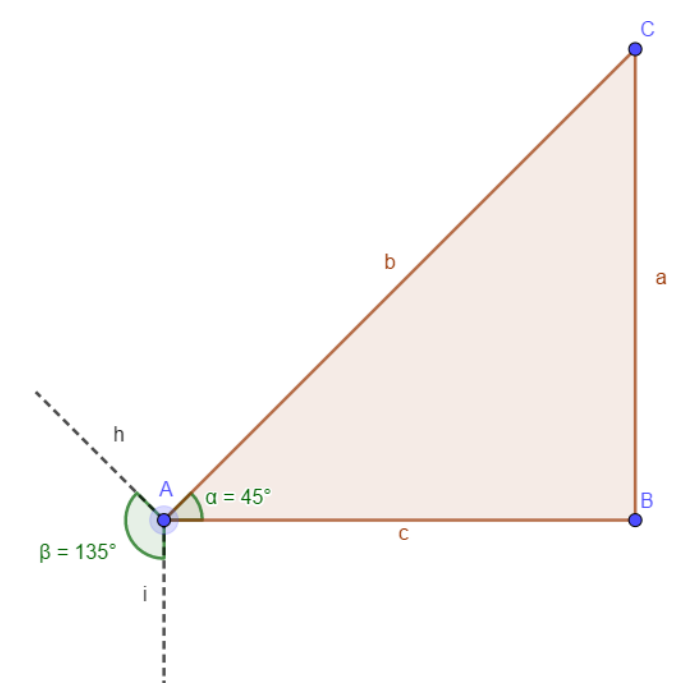

Fonte: Próprio autor

No triângulo retângulo, tiveram dificuldade para entender que o robô não faria uma curva de 45 graus e sim de 135 graus, pois o robô seguindo a linha, sua frente sempre deve estar perpendicular a ela, logo o giro do corpo do robô deve ser o ângulo beta representado na imagem 3. O conhecimento de ângulos, tipos de triângulos, ângulo complementar, suplementar e arco são conhecimentos necessários na elaboração da programação para girar o robô.

\section{Resultados}

Esperamos contribuir com esse relato extensionista, na divulgação de um processo de aproximação com a comunidade em socializar, um espaço e material que também é dela, em favor da motivação, do ensino e aprendizagem dos alunos que tiveram a oportunidade de vivenciar uma experiência com a Robótica Educacional e Matemática. As atividades realizadas exigiram dos alunos envolvidos, que possuíssem domínio de alguns conceitos básicos matemáticos, como divisão, multiplicação, soma e contagem, sem esquecer outros e que através deste ambiente de mutua aprendizagem puderam ver que teoria e prática estãoconectadas.

Saber explorar e trabalhar as dúvidas que os alunos emergem em uma aula de robótica, não é uma tarefa fácil, mas investigativa e construtiva, pois é necessária uma abordagem de orientação e de questionamento para que o aluno crie suas conjecturas, teste e chegue a uma conclusão. Muitas das vezes, não estamos preparados para tais eventos, pois os alunos nos surpreendem com suas 
curiosidades, e estes questionamentos surpresas e solução novas aos problemas que se tornam ponte para o novo conhecimento.

Outro ponto a ser destacado, e que foi observado durante a realização dos desafios, é que os alunos não aprofundaram somente os conteúdos matemáticos, mas também no decorrer da proposta de atividade houve momentos que os alunos desenvolveram o trabalho em equipe, respeito aos colegas, disciplina e foram mais ativos nas ações, se envolveram, buscaram, foram momentos de marcas, seja de cunho emocional como deconhecimento.

Nos questionários aplicados ao final, foi analisado o quão aquela experiencia foi marcante na vida deles, quanto no caráter emocional, tanto no processo de conhecimento deles, na maior parte, disseram que foi um momento único de interação, de aprendizagem, e que ficaria como exemplo que a matemática está em tudo que os rodeia.

Percebam que foi necessária uma situação problema para estimular e criar uma conexão com o conhecimento científico. Estes poucos exemplos dos alunos já mostram de maneira simples o quão o projeto foi uma experiência educativa, onde o aluno consegue adquirir conhecimento de forma lúdica. O ambiente de aprendizagem que Robótica Educacional desenvolve, desperta vários conhecimentos tanto matemático, desde o momento de montagem até a programação, onde na montagem o aluno se encontra diante de diversas relações geométricas, nas peças até na elaboração de desafios, como o proposto até momento.

Em nenhum momento foi repassado aos alunos a resposta "correta" dos cálculos, eles conseguiram demonstrar que aprenderam através da RE a conforme iam conseguindo concluir cada desafio, ao conclui-los mostraram que utilizaram do que aprenderam ali, pois para que concluíssem os cálculos deveriam estar coerentes. Porém ficará como forma de melhora para as futuras ações, que deixemos os alunos, mas livres e que eles possam desenvolverem ainda mais suas logicas e conjecturas, e não ficarmos presos a repassar fórmulas prontas.

Assim, percebemos na Robótica Educacional uma boa ferramenta para potencializar o processo de ensino e aprendizagem da matemática, ligada é mais uma tecnologia digital, pensando em alunos que estão imersos nesse contexto, seja a através de meios de comunicação, na rotina doméstica e até mesmo no lazer. E para aquelas crianças que não vivem uma cultura digital, é uma oportunidade de experienciar o novo, de criar, de produzir. A Robótica pôde instigar nos alunos a curiosidade, tanto no seu funcionamento final como no seu processo de construção, promovendo um momento para se aplicar conhecimentos prévios dos alunos, mostrando a importância de se compreender os conteúdos matemáticos. 


\section{Agradecimentos}

Agradecemos a Universidade Federal de Goiás, ao PROBEC, a todas as escolas que apoiaram nosso projeto e aos alunos que foram essenciais nesta pesquisa.

\section{Referências}

BARBOSA, F. C.; SOUZA JUNIOR, A. J. Robótica educacional no ensino fundamental público: uma arte de fazer. Anais do XI Encontro Nacional de Educação Matemática, Curitiba - PR, 2013.

BARBOSA. Fernando C. Rede de aprendizagem em robótica: uma perspectiva educativa de trabalho com jovens. UFU, Uberlândia- MG, 2016.

FAJER, Marcia. Sistema de investigação dos acidentes aeronáuticos da aviação geral - uma análise comparativa. São Paulo: USP, 2009.

MAHMUD, D. A. O uso de robótica educacional como motivação a aprendizagem de matemática. 2017. 82f. Dissertação (Mestrado Profissional) - Sociedade Brasileira de Matemática - SBM; Fundação Universidade Federal do Amapá - UNIFAP.

MIRANDA, L. C.; SAMPAIO, F. F.; BORGES, J. A. S. RoboFácil: Especificação e Implementação de um Kit de Robótica para a Realidade Educacional Brasileira. Publicado na Revista Brasileira de Informática na Educação, Volume 18, Número 3, 2010.

PAPERT, Seymour. A máquina das crianças: repensando a escola na era da informática. Tradução Sandra Costa.- ed. ver. - Porto Alegre: Artmed, 2008.

PAPERT, Seymour. Logo: computadores e educação. Tradução de José Armando Valente, Beatriz Bitelman e Afira V. Ripper. 2. ed. São Paulo: Brasiliense, 1985.

REY, F. G. Pesquisa Qualitativa e Subjetividade: os processos de construção da informação. Tradução de Marcel Aristides Ferrada Silva. São Paulo: Pioneira Thomson Learning, 2005.

SILVA, Alzira Ferreira da. RoboEduc: uma metodologia de aprendizado com robótica educacional. Natal, RN: UFRN, 2009.

ZILLI, Silvana de Rocio. A Robótica Educacional no ensino fundamental: perspectivas e práticas. Florianópolis: UFSC, 2004. 